\title{
Selecting of heating by gas radiant heaters in relation to the new ecodesign requirements on the example of large-cubage halls
}

\author{
Edyta Dudkiewicz ${ }^{1, *}$ \\ ${ }^{1}$ Wroclaw University of Science and Technology, Faculty of Environmental Engineering, Wybrzeże \\ Wyspiańskiego 27, 50-370 Wroclaw, Poland
}

\begin{abstract}
According to the schedule of the European Commission's product efficiency policy in force, as specified in European Union Commission Regulation of 28 April 2015, new requirements for local space heaters are in effect from 1 January 2018. The paper provides current definitions of appliances, including gas radiant heaters, intended for commercial applications. The requirements resulting from current regulations and respective changes substantial for manufacturers and investors are presented. Gas consumption cost calculations and accumulated cost analysis for 10-year period for two types of heaters, those of the lowest and the highest value of seasonal space heating energy efficiency, are exhibited. This is a reliable parameter essential for selecting the appliance, and its value is calculated and presented according to new regulations.
\end{abstract}

\section{Introduction}

The Ecodesign and Energy Labelling Directives, called together ErP (Energy-related Products), form the basis of the European Commission's product efficiency policy. Ecodesign (Directive 2009/125/EC [1]) sets minimum performance requirements for new products entering the EU market, whereas Energy Labelling (Directive 2017/1369/EU [2]) informs consumers on product energy efficiency. These Directives make a significant contribution to Europe's energy efficiency and climate targets and has been the subject of many studies conducted over the last years [3-6]. According to ErP is estimated of the EUs target energy reduction of $20 \%$ by 2020 , the reference point is 1990 [1,4]. The website of Polish Ministry of Energy [7] includes the implementing regulations for the Directive [1], which refer to various groups of energy-related appliances affecting the natural environment.

Heating and cooling are the EU's biggest energy-consuming sectors. Much of energy is wasted through insufficient insulation or inefficient heating system in buildings [3]. Furthermore the external conditions such as wind or sunlight have significant impact on energy consumption especially in industrial halls [8]. The bibliography includes research results for energy consumption both in residential buildings and in public buildings (Fig. 1).

\footnotetext{
${ }^{*}$ Corresponding author: edyta.dudkiewicz@pwr.edu.pl
} 
Relatively high consumption of energy is stated for hall-type building (large cubage units of commercial, industrial, warehouse and sport applications). In non-residential buildings, the majority of energy is used for heating, ventilation and air conditioning (37\% in total), then for lighting (32\%) and then for electrical and process equipment $(24 \%)$ [9, 10]. Fig. 1 shows energy consumption in various kind of non-residential buildings. Given in fig. 1 [9] the indexes: EP - primary energy refers to the non-renewable energy level, whereas EK to final energy. The index EP determines the energy level included in sources, necessary to cover the heat demand for heating, ventilation and hot water production. The index of final energy (EK) pertain to energy demand when the equipment efficiency is taken into account. $[9,10]$.

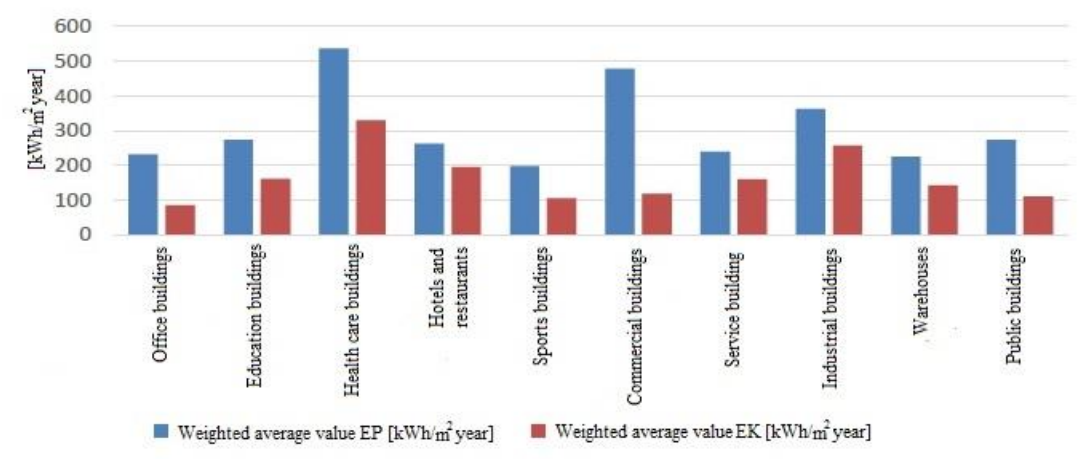

Fig. 1. Energy consumption in various kind of non-residential buildings [9].

In order to reduce high running costs related to high energy prices, appropriate solutions in strategy, technology and management fields need to be undertaken for large-cubage halls. Respective tools shall be used for this purpose due to high demands laid down for heating systems, namely:

- reasonably low investment expenses and running costs, however providing appropriate heat conditions for employees or for related processes,

- $\quad$ high efficiency and reliability of the system,

- suitable software and automatic control of heating process,

- application of energy-saving and ecological solutions with heat recovery and having no harmful effect on natural environment.

Specific construction aspects of large-cubage building and the way of its running make it necessary to analyse many factors when the heating system is considering [10]. a common way of heating the halls consists in application of radiant heaters (of water, gas or electric types). Proper solution is affected by specific conditions inside the hall and the utility infrastructure available on site.

The aim of the article is presentation of designing rules of heating by gas radiant heaters in relation to the new ecodesign requirements.

\section{Local space heaters}

Regulation [11] sets out 31 new definitions. Three of them will be quoted here: local space heater, luminous local space heater and tube local space heater. The first definition presents general description of appliances, the regulation refers to, while the two next ones apply to radiating equipment used for heating large-cubage halls. It is worth providing definitions and full names of these appliances (also in Polish) as various descriptions for these group of appliances are used in data sheets and bibliography: 
- "local space heater"- means a space heating device that emits heat by direct heat transfer or by direct heat transfer in combination with heat transfer to a fluid, in order to reach and maintain a certain level of human thermal comfort within an enclosed space in which the product is situated, possibly combined with a heat power to other spaces and is equipped with one or more heat generators that convert electricity or gaseous or liquid fuels directly into heat, through use of the Joule effect or combustion of fuels respectively [11];

- "luminous local space heater (ceramiczny promiennik podczerwieni - pl.) means a local space heater, using gaseous or liquid fuel which is equipped with a burner; which is to be installed above head level, directed towards the place of use so that the heat emission of the burner, being predominantly infrared radiation, directly warms the subjects to be heated and which emits the products of combustion in the space where it is situated [11] (fig. 2 left);

- "tube local space heater" (rurowy promiennik podczerwieni - pl.) means a local space heater, using gaseous or liquid fuel, which is equipped with a burner; which is to be installed above head level, near the subjects to be heated, which heats the space primarily by infrared radiation from the tube or tubes heated by the internal passage of products of combustion and of which the products of combustion are to be evacuated through a flue duct [11] (fig. 2 right).
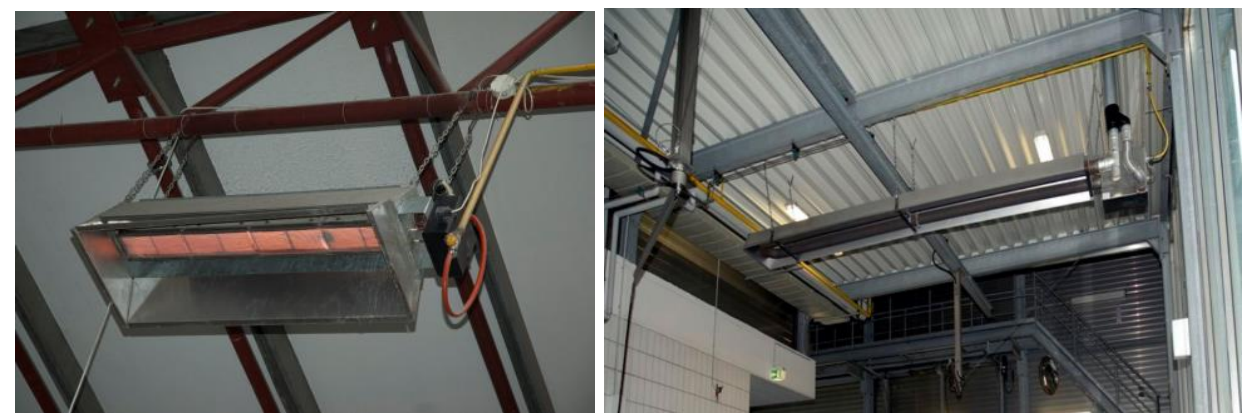

Fig. 2. Luminous local space heater (left) and tube local space heater (right).

Gas infrared heaters are subdivided due to the way of gas/air mixture combustion (on ceramic plate/in tube) and the way of flue gas discharge (into the room/outside the room). Additionally, according to the regulation [11], local space heaters are divided into those for domestic use and for commercial purposes, the latter include luminous and tube infrared radiant heaters. The requirements for the Energy Labelling and the provision of supplementary product information on local space heaters with a nominal heat power of $50 \mathrm{~kW}$ or less are given in [12], but it should be noted that there are no Energy Label existing for gas radiant heaters what is described in sec. 2.1.

\subsection{Ecodesign requirements for gas radiant heaters}

Specific ecodesign requirements for seasonal space heating energy efficiency in relation to EU 2015/1188 [11] are presented in Tab. 1.

Table 1. Ecodesign requirements for seasonal space heating energy efficiency of gas heaters [11].

\begin{tabular}{|c|c|c|c|}
\hline $\begin{array}{c}\text { Gas radiant } \\
\text { space heater }\end{array}$ & $\begin{array}{c}\text { Seasonal space heating } \\
\text { energy efficiency } \eta_{s}\end{array}$ & Emissions of NOx & $\begin{array}{c}\text { Date of apply of } \\
\text { requirements }\end{array}$ \\
\hline luminous & $85 \%$ & $200 \mathrm{mg} / \mathrm{kWh}$ input & 1 January 2018 \\
\hline tube & $74 \%$ & $200 \mathrm{mg} / \mathrm{kWh}$ input & 1 January 2018 \\
\hline
\end{tabular}


Given in Tab. 1 seasonal space heating energy efficiency $\left(\eta_{s}\right)$ means the ratio between the space heating demand, supplied by a local space heater and the annual energy consumption required to meet this demand, expressed in \%. The seasonal space heating energy efficiency (seasonal efficiency) of commercial local space heaters is defined as [11]:

$$
\eta s=\eta s, o n-F(1)-F(4)-F(5)
$$

where:

- $\eta$ s,on is the seasonal space heating energy efficiency in active mode (operation mode), expressed in \%,

$-F(1)$ is a correction factor accounting for a positive contribution to the seasonal space heating energy efficiency of electric storage local space heaters due to adjusted contributions for options for heat storage and heat power; and a negative contribution due to adjusted contributions for options for the heat power, expressed in $\%$;

$-F(4)$ is a correction factor accounting for a negative contribution to the seasonal space heating energy efficiency by auxiliary electricity consumption, expressed in $\%$;

$-F(5)$ is a correction factor accounting for a negative contribution to the seasonal space heating energy efficiency by energy consumption of a permanent pilot flame, expressed in $\%$.

Methods of calculated specific parameters in equation (1) were presented in annex III EU 2015/1188 [11]. It should be noted that there are no Energy Label existing for gas radiant heaters, determined in accordance with EU 2015/1186 [12]. The Energy Label is created for the information of end consumers to make their buying decisions of energy using products easier. For gas radiant heaters (for commercial purposes), used in a professional, industrial environment (and typically selected by specialists) there is no Energy Label existing because no energy labelling requirements relating to them are set in this Regulation. As the typical use and therefore also energy consumption of local space heaters is different to that of other space heating products being regulated, this Regulation didn't introduce a labelling scale different to that of other space heating products.

Furthermore what is very important that for local space heaters the technical documentation shall include two very important technical parameters: thermal efficiency and radiant factor. Many manufacturers of radiant heaters specify only their thermal efficiency in their data sheets, however, it is not the sufficient parameter for selecting the installed power and number of appliances. Radiant heaters deliver heat to space by means of radiation and convection, a significant amount of market available units transfer from $45 \%$ to $55 \%$ of heat by convection, the kind of heat which is, as considering heating, the lost heat as it is kept under the ceiling of the room $[13,14]$. Determination of the radiant factor requires very expensive examinations according to the standard EN 419-2 [15] for luminous radiant heaters and according to the standard EN 416-2 [16] for tube radiant heaters. These examinations are made in several laboratories in Europe and, so far, they are not run in Poland [13]. The new European requirements will cause that the data plate of appliance could enable to determine the energy efficiency, calculated on the basis of thermal efficiency and radiant factor, and the cheapest appliance which do not meet the regulations, especially those of low radiant factor would no longer be available on the market. Many leading manufacturers on European market had to cease production of radiant heaters which seasonal efficiency did not meet current regulations.

\subsection{Selecting gas radiant heaters}

Higher efficiency class radiant heaters cost more. What should be however noted, in case of a hall with known heat demand, a smaller number of units can be installed with the same heat power but with higher seasonal efficiency. As many data sheets provide no 
information about radiant efficiency, the radiant heaters were frequently badly selected basing on their heat power only. This has lead to poor heating of a hall and complaints of employees. Now, using the seasonal efficiency, we can use a simplified way to determine necessary number of radiant heaters for a hall of known heat demand. We should be aware that proper selection of equipment is affected by many other factors, like e.g. mounting height and installation possibilities, overhead cranes, etc. According to the guidelines [14], the power of equipment, for a halls with radiant heaters, can be reduced by about $20-30 \%$ with respect to the heat demand. Hence, assuming for the hall where heat demand $600 \mathrm{~kW}$ is reduced by $20 \%$ (due using radiant heaters) to $480 \mathrm{~kW}$ the Table 2 shows the relation between the number of tube radiant heaters and the seasonal efficiency, and also the installed heat power. We should note that the radiant temperature distribution in the hall is better for a smaller number of higher power heaters and installed at higher level than for higher number of lower power heaters installed at lower level [17]. In case of radiant heaters with the power $15 \mathrm{~kW}$ and low efficiency RF (55.7\%), it is necessary to install $15 \%$ more units than in case of the radiant heaters with seasonal efficiency equal to $89.2 \%$. For radiant heaters with higher heat power, despite the differences in values of RF coefficients, it is possible to install just one radiant less with the highest efficiency. The investment expenditures for particular types of radiant heaters differ significantly, hence the profitability of particular schemes of investment will be determined by analysing the cost of gas consumption in heating season.

In tube gas radiant heaters, the gas/air mixture is combusted inside the tube and the flue gas is discharged via flue gas duct outside the room. It is possible to recover heat from hot flue gas and use it by application of a proper heat exchanger. Various heat recovery technologies based on heat exchangers are now available on the market for heating systems with gas radiant heaters [18]. In case of tube radiant heaters more and more common is a flue gas/air heat exchanger which heats air delivered to zones with workers. Heat recovery in the exchanger is estimated at $15-20 \%$ while the investment expenditures for heat recovery from flue gas can amount even as much as up to $70 \%$ of total costs of the heating system, hence detailed analysis of the profitability is necessary.

Table 2. Relationship between tube heaters' amount and seasonal efficiency.

\begin{tabular}{|c|r|r|r|r|r|r|r|r|r|}
\hline Nominal heat power [kW] & \multicolumn{3}{|c|}{$\mathbf{1 5}$} & \multicolumn{3}{|c|}{$\mathbf{3 0}$} & \multicolumn{3}{|c|}{$\mathbf{4 9}$} \\
\hline Thermal efficiency [\%] & 81.6 & 82.9 & 82.7 & 82.3 & 82.3 & 85.0 & 82.3 & 82.2 & 81.4 \\
\hline Radiant factor RFnom [\%] & 55.7 & 65.3 & 77.8 & 59.9 & 70.2 & 76.7 & 60.2 & 70.8 & 77.3 \\
\hline Seasonal efficiency [\%] & 75.7 & 82.0 & 89.2 & 79.5 & 84.5 & 91.9 & 80.2 & 85.2 & 88.3 \\
\hline $\begin{array}{c}\text { Amount of tube heaters } \\
\text { [units] }\end{array}$ & 42 & 39 & 36 & 20 & 19 & 18 & 12 & 11 & 11 \\
\hline Installed heat power [kW] & 634 & 585 & 538 & 604 & 568 & 522 & 599 & 563 & 544 \\
\hline
\end{tabular}

\section{Analysis of annual cost for fuel gas}

As it is possible to determine the parameters of radiant heaters unambiguously, we are able to run economic analysis of gas consumption costs for production hall heated with radiant heaters. A large-cubage hall with heat demand, as calculated according to the standard PN-EN12831 [19], of Q $=600 \mathrm{~kW}$ was assumed for analysis. Two types of Schwank tube radiant heaters were considered [20]. Their specifications, in line with the requirements [11], were shown in Table 3. Furthermore, Table 3 provides the results of their selection. The heaters selected are those with the lowest and the highest seasonal efficiency among heaters of this manufacturer. It was assumed that the radiant heaters are operated 960 hours a year. According to Energy Law, the hall under consideration qualifies for W5-1 tariff due to the scale of charges at Polska Spółka Gazownictwa Sp. z o.o. (Gas Operator, Ltd.). Gas 
prices for final users in Poland are officially approved by the President of URE (Energy Regulatory Authority). Currently, there are eight main gas providers which may give discounts from scale tariff prices, so it is possible to find an offer 5-10\% lower than the official tariff of PGNiG (Polish Oil and Gas Company) [21]. In the analysis, the tariffs applied for distribution services for Wrocław City were used. The analysis of annual cost of gas fuel is shown in Table 4. As result from the analysis, annual cost of gas fuel is $18 \%$ lower for radiant heaters with the highest seasonal efficiency. A simple economic analysis for accumulated costs was made. The purchase cost of Infra radiant heaters is PLN $305 \mathrm{~K}$, while that of SuperTube radiant heaters is PLN $435 \mathrm{~K}$. Figure 3 shows the results of economic analysis in the form of accumulated cost diagrams. After 7 years these costs are levelled off, while in successive years the accumulated costs are lower for the highest efficiency radiant heaters.

Table 3. Technical parameters acc. [11] of local space heaters used to analysis.

\begin{tabular}{|c|c|c|}
\hline & Infra Schwank D 15/1 L & SuperTube 620/M+ \\
\hline Nominal heat power [kW] & 15.0 & 19.0 \\
\hline Minimum heat power [kW] & - & 14.3 \\
\hline Min. heat power - \% of nominal heat power & - & $25 \%$ \\
\hline Thermal efficiency [\%] at nom. heat power & $81.6 \%$ & $85.9 \%$ \\
\hline Thermal efficiency [\%] at min. heat power & - & $85 \%$ \\
\hline Radiant factor RF nom [\%] at nom. heat power & $55.7 \%$ & $77.6 \%$ \\
\hline Radiant factor RF min [\%] at min. heat power & - & $75.7 \%$ \\
\hline Auxiliary electricity consumption [kW] & & \\
- at nominal heat power & 0.1 & 0.1 \\
- at minimal heat power & - & 0.1 \\
\hline Heat power control type & $1-$ stage & Mod. \\
\hline Space heating emissions NOx [mg/kWh] & 122 & 118 \\
\hline Seasonal efficiency [\%] & $75.7 \%$ & $92.9 \%$ \\
\hline Amount of tube heaters [units] & 42 & 27 \\
\hline Gas consumption [m $\mathbf{3} / \mathbf{h}]$ & 1.5 & 1.91 \\
\hline Annual gas consumption [kWh/rok] & 676712 & 554324 \\
\hline Installed heat power [kW] & 634 & 517 \\
\hline Tube heater price [euro nett] & 1400 & 3100 \\
\hline Installation cost [PLN gross] & 305729 & 435500 \\
\hline
\end{tabular}

Table 4. Annual cost for gas fuel.

\begin{tabular}{|c|c|c|c|}
\hline & Infra Schwank D 15/1 L & SuperTube $620 / M+$ \\
\hline \multicolumn{2}{|c|}{ Gas fuel price [PLN] } & 84500 & 69505 \\
\hline \multicolumn{2}{|c|}{ Subscription fee } & 1786 & 1786 \\
\hline \multirow[t]{2}{*}{ Distribution fee } & fixed & 4120 & 3375 \\
\hline & variable & 15199 & 12450 \\
\hline \multicolumn{2}{|c|}{ Annual cost [PLN gross] } & 105955 & 87116 \\
\hline
\end{tabular}




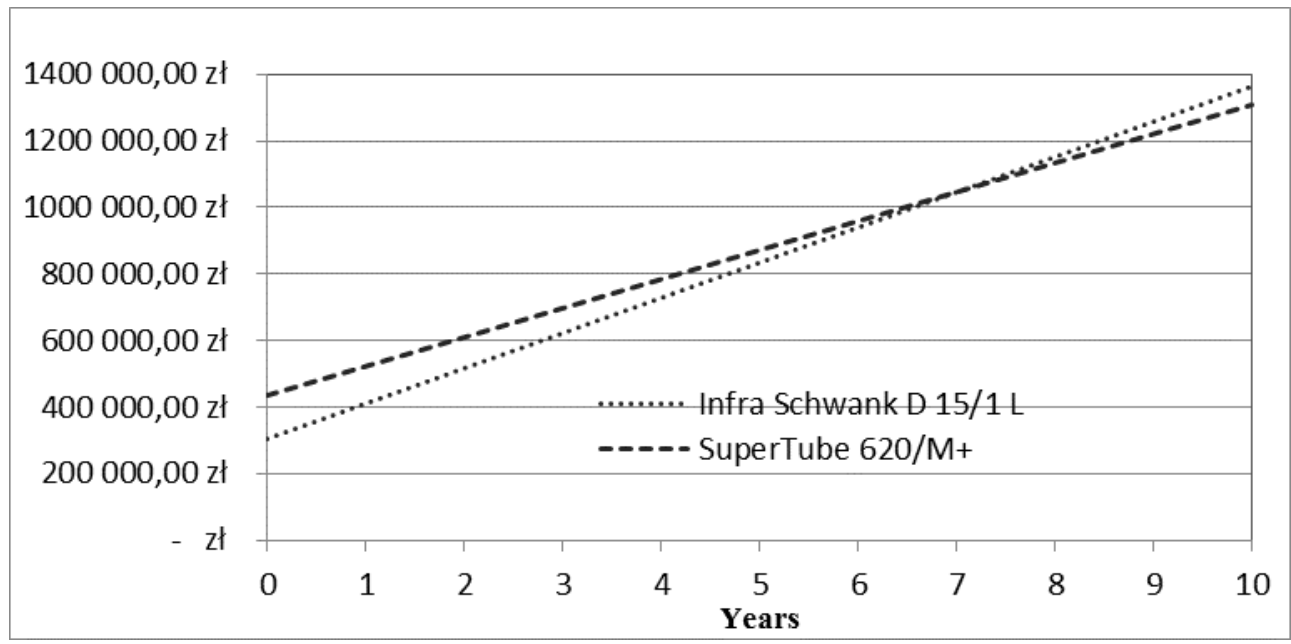

Fig. 3. Diagrams of accumulated costs for two types of tube local space heaters.

\section{Conclusion}

Ambiguous information about efficiency of radiant heaters as they so far appeared in data sheets caused a confusion on the market and problems with selection and sizing of these units. The new requirements consistent with ErP cause that we can now unambiguously determine the heat power of an appliance, radiation factors, energy efficiency index and energy efficiency class. For luminous local space heater seasonal space heating energy efficiency has to be greater than 85 , and tube local space heaters need to have energy efficiency greater then 74. We should note that there are no Energy Label existing for gas radiant heaters. At the beginning of next year (2019) it would be documented radiation factors and seasonal efficiency values for radiant heaters. This will describe the energy consumption much more detailed as any ABC-label.

When selecting the radiant heaters we should follow the energy efficiency index. The higher the seasonal efficiency is, the smaller number of radiant heaters of the same power will be installed in the hall. The differences in the number of appliances installed are especially demonstrated for low power units. Available on the market are tube radiant heaters with seasonal efficiency from $75 \%$ (according to the regulations in force) up to $92 \%$. Individual prices of the heaters differ from each other significantly, hence prior selecting them, it would be advisable to run the cumulated cost analysis. According to the analysis, the investment costs of the most expensive heaters (with the highest value of seasonal efficiency) are $42 \%$ higher than those for the radiant heaters with the lowest seasonal efficiency, however, after only 7 years the accumulated costs become equal.

As it is possible to select various heating systems with gas radiant heaters and also to recover heat from the units, the cost analysis should be made to find the most profitable solution. The new requirements for the equipment and regulations about their description allow to run reliable economic analysis of related costs.

The work was realized within the allocation No. 0401/0007/17 awarded for Faculty of Environmental Engineering Wroclaw University of Science and Technology by Ministry of Science and Higher Education in years 2017-2018. 


\section{References}

1. EU, 2009. Ecodesign Directive 2009/125/EC. Official Journal of the European Union, Brussels

2. EU 2017/1369 of the European Parliament and of the Council of 4 July 2017 setting a framework for Energy Labelling and repealing Directive 2010/30/EU

3. M. Calero-Pastor, F. Mathieux, D. Brissaud, L. Castellazzi, Energies, 10 (2017)

4. D. Hinchliffe, F. Akkerman, J. Cleaner Production, 168 (2017)

5. N.F. Nissen, Waste Electrical and Electronic Equipment Handbook (Woodhead Publishing Ltd., Cambridge, 2012)

6. A. De Almeida, B. Santos, F. Martins, Energy Efficiency, 9 (2016)

7. The website of the Ministry of Energy: http://www.egospodarka.gov.pl/Energetyka/Efektywnosc+energetyczna/Ekoprojekt [18.01.2018]

8. A. Żabnieńska-Góra, ASEE17, E3S (2017)

9. Financing of buildings' energy efficiency improvement in Poland (in Polish), BPIE, Warszawa (2016)

10. E. Dudkiewicz, Nowoczesne Hale (2017)

11. EU 2015/1188 of 28 April 2015 implementing Directive 2009/125/EC of the European Parliament and of the Council with regard to ecodesign requirements for local space heaters

12. EU 2015/1186 of 24 April 2015 supplementing Directive 2010/30/EU of the European Parliament and of the Council with regard to the Energy Labelling of local space heaters

13. E. Dudkiewicz, N. Fidorów, J. Jeżowiecki, Annual Set The Environment Protection 11, 2 (2009)

14. J. Cihelka, Ogrzewanie przez promieniowanie (Arkady, Warszawa, 1965)

15. EN 419 -2 Non-domestic gas-fired overhead luminous radiant heaters - Part 2: Rational use of energy

16. EN 416-2 Single burner gas-fired overhead radiant tube heaters for non-domestic use - Part 2: Rational use of energy

17. E. Dudkiewicz, J. Jeżowiecki, Research on heat field in halls heated with gas infrared radiators (PAN, Lublin, 2007)

18. E. Dudkiewicz, Rynek Instalacyjny, 12 (2016)

19. PN-EN 12831-1:2017-08 Energy performance of buildings - Method for calculation of the design heat load - Part 1: Space heating load, Module M3-3

20. The website http://www.schwank.de/ [18.01.2018]

21. The website https://enerad.pl/rynek-energii/rynek-gazu/gaz-dla-firmy/ [18.01.2018] 